\title{
Distinguishing Exudative from Transudative Effusion by Using Pleural Fluid Cholesterol and Bilirubin in Comparative Study to Light's Criteria
}

\author{
Hanaa Jabbar Ismail ${ }^{1}$, Haider Abdulhameed Alqaraghuli ${ }^{2}$, Hashim Mahdi Hashim ${ }^{3}$ \\ ${ }^{1}$ Dr. Specialism, Health Department-employment in Ministry of Health/Iraq, \\ ${ }^{2}$ Lecturer, ${ }^{3}$ Prof., Internatal Medicine Department/College of Medicine, Al-Nahrain University/Iraq
}

\begin{abstract}
Background: Pleural effusions are often classified into exudates and transudates based on certain biochemical parameters which include protein; lactate dehydrogenase (Light's criteria); cholesterol and bilirubin, so the aim of the study is to evaluate the importance of pleural fluid cholesterol and bilirubin in differentiating exudative from transudate pleural effusion.
\end{abstract}

Method: Fifty patients with pleural effusion were evaluated for pleural fluid protein, lactate dehydrogenase (LDH), cholesterol and bilirubin and compared simultaneously with drawn blood sample for protein, LDH and bilirubin.

Results: In this study cholesterol in pleural fluid has a 94\%, 100\% sensitivity and specificity respectively and bilirubin ratio (pleural fluid bilirubin/serum bilirubin) has a sensitivity of $88 \%$ and specificity of $85 \%$ while the parameters of Light's criteria i.e. protein ratio (fluid protein/serum protein) has $88 \%, 85 \%$ sensitivity and specificity respectively and LDH ratio (fluid LDH/serum LDH) has a sensitivity of $100 \%$ and specificity of $71 \%$.

Conclusion: Pleural fluid cholesterol and bilirubin ratio have a better sensitivity and specificity in differentiating exudative from transudative pleural effusion than the parameters of Light's measures.

Keywords: Pleural fluid cholesterol, bilirubin, exudative transudate effusion.

\section{Introduction}

The internal surfaces of the thoracic cavity are cover by pleura, includes a cover of mesothelial cells held up by a net of connective plus fibro elastic tissue. Usually, a small amount of fluid within the pleural space works like a lubricant to decrease friction amid chest wall and lung at inspiration and expiration. This fluctuation of

\footnotetext{
Corresponding Author:

Hashim Mahdi Hashim

Dr. Specialism, Health Department-employment in

Ministry of Health/Iraq

e-mail: qaisajam1981@gmail.com
}

fluid is based on the oncotic in addition to hydrostatic pressures within the parietal plus visceral pleura as well as the pressure inside the pleural space its own. Fluid is drained out mostly through lymphatics within the parietal pleura $^{(1)}$. Transudative pleural effusions derive from general illnesses that may not directly affect the pleura but alternatively provide an asymmetry of Starling's forces, ending in moving of fluid within the pleural space. The analysis for transudates involve recognition of the systemic illnesses like nephrotic syndrome, congestive heart failure and cirrhosis with ascites. Treating these effusions is done by management of the underlying illness. After injury that occur in pleural surface, exudative effusions result. Intrapleural illness can be suggested by the presence of exudative effusion $^{(2)}$. In order to differentiate exudative from 
transudative pleural effusion,Light et al established ${ }^{(3)}$ a criteria to do so with sensitivity $99 \%$ and specificity $98 \%$ that include pleural protein/serum protein of $>0.5$, pleural LDH/serum LDH of $>0.6$ and an estimated level of LDH in the pleural fluid more than two thirds LDH serum level. Yet other studies investigating Light's criteria showed a specificity of $70-86 \%$ and about $25 \%$ of cases identified by Light's criteria to have exudative pleural effusion have a transudate effusion ${ }^{(4)}$. It has been found by Meta-analysis study on this subject that there is no single test could clearly differentiate between transudative and exudative pleural effusion ${ }^{(5,6)}$. Leukocytes and erythrocytes' degeneration will increase the concentration of cholesterol inside pleural cavity. Another theory is that cholesterol of pleura originates from plasma; $70 \%$ of plasma cholesterol islow density lipoproteins (LDL), and the rest is very low density lipoproteins (VLDL) or high density lipoproteins (HDL), so plasma cholesterol enter $\mathrm{P}$ the pleural cavity after increased permeability of pleural vessels ${ }^{(7)}$. Pleural fluid bilirubin with pleural serum ratio of $>0.6$ is suggestive of an exudate with a sensitivity and specificity of $90.6 \%$ and $96.2 \%$, respectively ${ }^{(8)}$. In non-diagnosed exudative effusions measuring the glucose level is of particular importance in which a decreased glucose level in the pleural fluid $(<60 \mathrm{mg} / \mathrm{dL})$ can limit the possible diagnosis to either on of these: rheumatoid and tuberculous effusion, Para pneumonic and hemothorax or malignant effusion and the Churg-Strauss syndrome ${ }^{(9)}$. In Parapneumonic effusion, glucose level in pleural fluid $<40 \mathrm{mg} / \mathrm{dL}$, so for treatment this case needstube thoracostomy. In rheumatoid effusions a glucose level in pleural fluid $<30 \mathrm{mg} / \mathrm{dL}^{(10)}$. While in systemic lupus erythematosus (SLE) a glucose level in pleural fluid $>80 \mathrm{mg} / \mathrm{dL}^{(11)}$. In case of pleural effusion secondary to malignancy usually have a low glucose level and a positive cytology in the pleural fluid ${ }^{(12)}$. This study aims to assessing the value of pleural fluid bilirubin and cholesterol levels in differentiating the transudative from exudative pleural effusion in comparison to Light's criteria.

\section{Method}

A prospective study in which 50 patients with pleural effusion age ranges from 25-70 years where admitted at the medical department at Al-Imamein Kadhimein Medical City. The study period was conducted from April 2013 to January 2014. Thirty patients (60\%) were males and 20 patients $(40 \%)$ were females. Inclusion Criteria: Age $\geq 16$ years, patients with definite diagnosis of pleural effusion on clinical and radiological imaging.

Exclusion Criteria: Patients $<16$ years old, patients with undiagnosed pleural effusion, diagnosed patients who are on treatment,pleural effusion with renal insufficiency or pulmonary embolism because both can cause transudative and exudative effusion that can affect the result of our study. Following a thorough history, physical examination, the pleural effusion was confirmed and localized by chest X-ray . Diagnostic pleural fluid tapping was done in each case, in some cases ultrasound guided localization of effusion was done. The samples then were examined for glucose, white blood cell count, $\mathrm{LDH}$, cholesterol, bilirubin, protein, acid fast stain, Gram stain, bacterial culture, and cytology. The pleural effusions were categorized as exudative and transudative according to the causative etiology, the Light's criteria, pleural bilirubin/serum bilirubin $>0.6 \mathrm{mg} / \mathrm{dL}$ and cholesterol in pleural (considering a value of $45 \mathrm{mg} /$ dLas cutoff point).Statistical analysis: The measured biochemical parameters usefulness for identifying exudates was assessed with Bayesian method in order to calculate the sensitivity, specificity, positive predictive value (PPV), negative predictive value (NPV) and accuracy of each parameter. The statistical significance measured by $\mathrm{X} 2$ analysis to test differences between means. A $P$ value $<0.05$ considered significant.

\section{Results}

The mean age of the 50 patients included in the study was $51.6 \pm 14.9$ years (range, $25-70$ years); table 1 shows the age and gender distribution among patients with pleural effusion according to.

Table 1: The type of pleural effusion on clinical basis and its association with the sex $\&$ age:

\begin{tabular}{|l|c|c|c|c|}
\hline \multirow{2}{*}{$\begin{array}{l}\text { Type of pleural } \\
\text { effusion }\end{array}$} & \multirow{2}{*}{ No. (\%) } & Male No. (\%) & Female No. (\%) & \multirow{2}{*}{ Age (Mean \pm SD) Years } \\
\cline { 2 - 5 } & & $18(36 \%)$ & $18(36 \%)$ & $46.5 \pm 14.4$ \\
\hline Exudate & $36(72 \%)$ & $12(24 \%)$ & $2(4 \%)$ & $64.8 \pm 4.1$ \\
\hline Transudate & $14(28 \%)$ & $\mathbf{3 0}(\mathbf{6 0 \%})$ & $\mathbf{2 0}(\mathbf{4 0} \%)$ & $\mathbf{5 1 . 6} \pm \mathbf{1 4 . 9}$ \\
\hline Total & $\mathbf{5 0 ( 1 0 0 \% )}$ & & \\
\hline
\end{tabular}


In this study tuberculous effusion was the most common cause of pleural effusion in 24 patients (48\%), heart failure was the second most common cause in 10 patients $(20 \%)$, followed by malignancy in 8 patients $(16 \%)$, Para pneumonic effusion in 4 patients $(8 \%)$ and liver cirrhosis in 4 patients $(8 \%)$ as shown in table 2.

Table 2: The type of pleural effusion and its causes:

\begin{tabular}{|l|c|c|c|}
\hline Type of pleural effusion & No. (\%) & The cause & No. (\%) \\
\hline \multirow{2}{*}{ Exudate } & \multirow{3}{*}{$36(72 \%)$} & Tuberculosis & $24(48 \%)$ \\
\cline { 3 - 4 } & & Malignancy & $8(16 \%)$ \\
\cline { 3 - 4 } & \multirow{2}{*}{ Transudate } & Para pneumonic & $4(8 \%)$ \\
\cline { 3 - 4 } & \multirow{2}{*}{$14(28 \%)$} & Heart failure & $10(20 \%)$ \\
\hline Total & $50(100 \%)$ & Liver cirrhosis & $4(8 \%)$ \\
\hline
\end{tabular}

The practicality of each of the factors for recognizing exudate and transudate were evaluated in terms of sensitivity, specificity, positive predictive value (PPV), negative predictive value (NPV), accuracy and P-value as shown in table 3.

Table 3: Factors for identifying exudate and transudate

\begin{tabular}{|l|c|c|c|c|c|}
\hline Parameter & Sensitivity & Specificity & PPV & NPV & Accuracy \\
\hline Protein ratio & $88 \%$ & $85 \%$ & $94 \%$ & $75 \%$ & $88 \%$ \\
\hline LDH ratio & $100 \%$ & $71 \%$ & $90 \%$ & $100 \%$ & $92 \%$ \\
\hline Fluid cholesterol & $94 \%$ & $100 \%$ & $100 \%$ & $87 \%$ & $96 \%$ \\
\hline Bilirubin ratio & $88 \%$ & $85 \%$ & $94 \%$ & $75 \%$ & $88 \%$ \\
\hline
\end{tabular}

Table 4: Distinguishing exudative from transudative effusion in pleural according protein ratio \& fluid cholesterol

\begin{tabular}{|l|c|c|c|c|}
\hline \multirow{2}{*}{ Parameter } & \multicolumn{2}{|c|}{ Exudate } & \multicolumn{2}{c|}{ Transudate } \\
\cline { 2 - 5 } & No. & \% & No. & \% \\
\hline Protein ratio & 32 & 64 & 12 & 24 \\
\hline Fluid cholesterol & 34 & 68 & 14 & 28 \\
\hline P-value & \multicolumn{3}{|c|}{0.6} & \multicolumn{3}{|c|}{0.6} \\
\hline
\end{tabular}

Thirty two patients (64\%) had been diagnosed to have exudative pleural effusion and 12 patients (24\%) had been diagnosed to have transudative pleural effusion using fluid protein/serum protein ratio (protein ratio) while 34 patients $(68 \%)$ had been diagnosed to have exudative pleural effusion and 14 patients $(28 \%)$ had been diagnosed to have transudative pleural effusion using fluid cholesterol. P-value $=0.6$ which means there is no significant difference between protein ratio and fluid cholesterol in differentiating exudative from transudative pleural effusion as shown in table 4.

Thirty two patients (64\%) had been diagnosed to have exudative pleural effusion and 12 patients $(24 \%)$ had been diagnosed to have transudative pleural effusion using fluid protein/serum protein ratio (protein ratio) while 32 patients $(64 \%)$ had been diagnosed to have exudative pleural effusion and 12 patients $(24 \%)$ had been diagnosed to have transudative pleural effusion using fluid bilirubin/serum bilirubin ratio (bilirubin ratio). There is no significant difference between protein ratio and bilirubin ratio in distinguishing exudative from transudative effusion of pleural $\mathrm{P}$-value $>0.05$ as shown in table 5 . 
Table 5: Diagnostic comparison between protein ratio $\&$ bilirubin ratio in distinguishing exudative from transudative effusion of pleura

\begin{tabular}{|l|c|c|c|c|}
\hline \multirow{2}{*}{ Parameter } & \multicolumn{2}{|c|}{ Exudate } & \multicolumn{2}{c|}{ Transudate } \\
\cline { 2 - 5 } & No. & \% & No. & \% \\
\hline Protein ratio & 32 & 64 & 12 & 24 \\
\hline Bilirubin ratio & 32 & 64 & 12 & 24 \\
\hline P-value & \multicolumn{2}{|c|}{1.0} & \multicolumn{2}{c|}{1.0} \\
\hline
\end{tabular}

Thirty six patients $(72 \%)$ had been diagnosed to have exudative pleural effusion and 10 patients $(20 \%)$ had been diagnosed to have transudative pleural effusion using fluid $\mathrm{LDH} /$ serum $\mathrm{LDH}$ ratio (LDH ratio) while 34 patients $(68 \%)$ had been diagnosed to have exudative pleural effusion and 14 patients (28\%) had been diagnosed to have transudative pleural effusion using fluid cholesterol. P-value $=0.6$ and 0.3 which means there is no significant difference between LDH ratio and fluid cholesterol in differentiating exudative from transudative pleural effusion as shown in table 6 .

Table 6: Distinguishing exudative from transudative effusion in pleural according LDH ratio \& fluid cholesterol.

\begin{tabular}{|l|c|c|c|c|}
\hline \multirow{2}{*}{ Parameter } & \multicolumn{2}{|c|}{ Exudate } & \multicolumn{2}{c|}{ Transudate } \\
\cline { 2 - 5 } & No. & \% & No. & \% \\
\hline LDH ratio & 36 & 72 & 10 & 20 \\
\hline Fluid cholesterol & 34 & 68 & 14 & 28 \\
\hline P-value & \multicolumn{2}{|c|}{0.6} & \multicolumn{2}{c|}{0.3} \\
\hline
\end{tabular}

Thirty six patients (72\%) had been diagnosed to have exudative pleural effusion and 10 patients $(20 \%)$ had been diagnosed to have transudative pleural effusion using fluid LDH/serum LDH ratio (LDH ratio) while 32 patients $(64 \%)$ had been diagnosed to have exudative pleural effusion and 12 patients $(24 \%)$ had been diagnosed to have transudative pleural effusion using fluid bilirubin/serum bilirubin ratio (bilirubin ratio). There is no significant difference between $\mathrm{LDH}$ ratio and bilirubin ratio in distinguishing exudative from transudative effusion of pleura.

\section{Discussion}

From all 50 cases included in the study, $72 \%$ of them (36 patients) found to had exudative effusion, and $28 \%$ of them (14 patients) found to had transudative effusion based on the clinical diagnosis as shown in table 1 . Tuberculosis being the most common diagnosis in exudative pleural effusion with a $48 \%$ (24 patients) followed by malignancy $\{8$ patients $(16 \%)\}$ as shown in table 2,this result is consistent with C. K. Liam et al study that showed tuberculosis as one of the most common causes of exudative effusion of pleura ${ }^{(13)}$. In our study using light's criteria the results had a sensitivity of $88 \%$ for protein ratio and $100 \%$ for $\mathrm{LDH}$ ration with a specificity of $85 \%$ for protein ratio and $71 \%$ for $\mathrm{LDH}$ ratio as shown in table 3 . According to Light et al study the difference between exudative and transudative effusion of pleural was done with high accuracy and nearly $100 \%$ sensitivity and specificity both using LDH and protein levels in both serum and pleural fluid ${ }^{(3)}$, being highly accurate and widely affordable the Light et al criteria had been the gold standard for initial categorization of pleural effusions. Yet many several followed studies failed to reproduce a similar excellent result. However many of the studies, used Light et al criteria showed that the sensitivity for exudates effusion identification mainly remain greater than $95 \%$, but the specificity had not exceed $78 \%{ }^{(14)}$. In this study 32 patients $(64 \%)$ had exudative pleural effusion and 12 patients $(24 \%)$ had transudative pleural effusion using fluid protein/serum protein ratio while 34 patients (68\%) had exudative pleural effusion and 14 patients $(28 \%)$ had transudative pleural effusion using pleural fluid cholesterol level. With a P-value of 0.6 means that the difference between pleural fluid cholesterol and protein ratio is statistically non-significant difference between exudative and transudative effusion of pleural, moreover, 36 patients (72\%) had exudative pleural effusion and 10 patients $(20 \%)$ had transudative pleural effusion using fluid $\mathrm{LDH} /$ serum LDH ratio while 34 patients $(68 \%)$ had exudative pleural effusion and 14 patients (28\%) had transudative pleural effusion using pleural fluid cholesterol level. P-value $=0.6$ and 0.3 which means there is no significant difference between $\mathrm{LDH}$ ratio and pleural fluid cholesterol level in differentiating exudative from transudative pleural effusion as shown in tables 4 and 6 respectively. Like studies done by Romero et al in which sensitivity plus specificity of Light's measures for the transudates and exudates, and diagnostic exactness of Light measures and how cholesterol in pleural cavity improve this diagnosis ${ }^{(15)}$. In another study done by Saad Abdul-Razzak Z. at 2001, he also found that pleural cholesterol level had a high sensitivity (100\%) in differentiating exudative from transudative pleural effusion and no significant difference between protein in pleural fluid and cholesterol level in the identification of transudative from exudative effusion ${ }^{(16)}$. In the current 
study 32 patients (64\%) had exudative pleural effusion and 12 patients $(24 \%)$ had transudative pleural effusion using fluid protein/serum protein ratio while 32 patients (64\%) had exudative pleural effusion and 12 patients (24\%) had transudative pleural effusion using fluid bilirubin/serum bilirubin ratio. $\mathrm{P}$-value $=1.0 \mathrm{which}$ means there is no significant difference between protein ratio and bilirubin ratio regarding the differentiation of transudative and exudative effusion also 36 patients (72\%) had exudative pleural effusion and 10 patients (20\%) had transudative pleural effusion using fluid LDH/ serum LDH ratio while 32 patients $(64 \%)$ had exudative pleural effusion and 12 patients (24\%) had transudative pleural effusion using fluid bilirubin/serum bilirubin ratio. $\mathrm{P}$-value $=0.3$ and 0.6 which means there is no significant difference between LDH ratio and bilirubin ratio in distinguishing exudative from transudative effusion of pleura as shown in table 5. This results also found in a study done by Meisel et al in which they found that the bilirubin qualifying measure comes to the wellaccepted LDH in addition to protein criteria and may even work as another qualifying measure to differentiate an exudative from transudative pleural effusions ${ }^{(17)}$.

\section{Conclusion}

For distinguishing exudative in addition to transudative pleural effusion. Computing pleural fluid cholesterol level carries a superior sensitivity, specificity in addition to positive predictive value comparing to Light's criteria parameters, and it is a more cost effective,easier and more efficient way in differentiating transudates from exudates along with the ratio of Pleural/serum bilirubin has the same advantage of cost effectiveness and the easiness.

Ethical Clearance: The Research Ethical Committee at scientific research by ethical approval of both environmental and health and higher education and scientific research ministries in Iraq

Conflict of Interest: The authors declare that they have no conflict of interest.

Funding: Self-funding

\section{References}

1. Dennis McCool F., Diseases of the diaphragm, chest wall, pleura and mediastinum, goldman's cecil medicine, 24th edition 2012; 99:607-609.

2. Martin L. Mayse, Non-malignant pleural effusions,
Fishman's pulmonary diseases and disorders, Fourth edition 2008; 85:1487-88.

3. Light W., Macgregor M.I., Luchsinger P.C. and W. C. BallJR., "Pleural effusions: the diagnostic separation of transudatesand exudates," Annals of Internal Medicine, 1972; 77, 507-513

4. Chakko S.C., S. H. Caldwell and P. P. Sforza, "Treatment of congestive heart failure. Its effect on pleural fluid chemistry," Chest, 1989; 95: 798-802.

5. Heffner JE, Brown LK, Barbieri CA. Diagnostic value of tests that discriminate between exudative and transudative pleural effusions. Chest 1997; 111:970-80.

6. D. K. Spady and j. M. Dietschy, "Cholesterol synthesis in vivo in 18 tissues of the squirrel monkey, guinea pig, rabbit, hamster and Rat," Journal of Lipid Research, 1983; 24:303-315.

7. Hamal A.B. et al., Pleural fluid cholesterol in differentiating exudative and transudative pleural effusion, 2013.

8. Meisel S., Shamiss A., M. Thaler, N. Nussinovitch and T. Rosenthal, "Pleural fluid to serum bilirubin concentration ratio for the separation of transudates from exudates," Chest, 1990; 98: 141-144.

9. In: Light RW, ed. Pleural diseases, 5th ed. Philadelphia: Lippincott, Williams \& Wilkins; 2007.

10. Lillington GA, Carr DT, Mayne JG: Rheumatoid pleurisy with effusion. Arch Intern Med 1971; 128:764-768.

11. Good JTJ, King TE, Antony VB, et al: Lupus Pleuritis: clinical features and pleural fluid characteristics with special reference to pleural fluid antinuclear antibodies. Chest 1983; 84:714718.

12. Sahn SA, Good JTJ: Pleural fluid PH in malignant effusions. Diagnostic, prognostic, and therapeutic implications. Ann Intern Med 1988; 108:345-349.

13. Liam C.K., Kim-Hatt L.I.M. and Wong C.M.M., Causes of pleural exudates in a region with a high incidence of tuberculosis, Respirology, 2000; 5: 33-38.

14. Romero Santiago, M.D.; Aifredo Candela, M.D.; Concepcion Martin, M.D.; Luis I-fernandez, M.D.; Celia Trigo, M.D.; T and Joan Gil, M.D., Different criteria for theseparation of pleural transudates from exudates, Chest/104/2/August 1993. 
15. Romero S, Candela A, Martin C, Hernandez L, Trigo C, Gil J, Evaluation of different criteria for the separation of pleural transudates from exudates, Chest 1993;104:399-404.

16. Abdul-Razzak Saad Z., M.B.Ch.B., Ibn Seena Teaching Hospital, The value of certain biochemical markers in the identification of exudative pleural effusion; 2001.
17. Meisel Simeha, M.Sc., M.D.; Arie ShamLis1, M.D.; Michael Thaler, M.D.; Naomi Nussinovitch, M.D.; and Talnta Rosenthal, M.D., Pleural fluid to serum bilirubin concentration Rratio for the separation of transudates from exudates, Chest/98/1/July, 1990. 